\title{
A simplified acute kidney injury predictor following transcatheter aortic valve implantation: ACEF score
}

\author{
Begum Uygur, Omer Celik, Ali Riza Demir, Ahmet Anil Sahin, Ahmet Guner, Yalcin Avci, Umit Bulut, Omer Tasbulak, \\ Gokhan Demirci, Fatih Uzun, Ali Kemal Kalkan, Mehmet Erturk
}

Cardiology Department, University of Health Sciences Turkey Istanbul Mehmet Akif Ersoy Thoracic and Cardiovascular Surgery Training and Research Hospital, Istanbul, Turkey

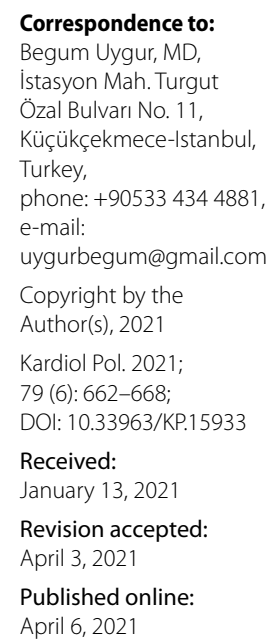

Correspondence to: Begum Uygur, MD, İstasyon Mah. Turgut Özal Bulvarı No. 11, Küçükçekmece-Istanbul, Turkey,

phone: +90533434 4881 e-mail: uygurbegum@gmail.com

Copyright by the Author(s), 2021

Kardiol Pol. 2021; 79 (6): 662-668: DOI: 10.33963/KP.15933

Received:

January 13, 2021

Revision accepted: April 3, 2021

Published online: April 6, 2021

\begin{abstract}
A B S TR A C T
Background: Transcatheter aortic valve implantation (TAVI) is an effective, less invasive treatment alternative for symptomatic severe aortic stenosis (AS). Acute kidney injury (AKI) following TAVI is a common complication and is associated with worse outcomes. The age, creatinine, ejection fraction (ACEF) score is a simple scoring method, including only three parameters: age, creatinine, and ejection fraction (EF). The score was well established in predicting AKI after coronary interventions.
\end{abstract}

Aims: We aimed to evaluate whether this simple scoring method, ACEF, may predict a development of AKI in patients who underwent TAVI.

Methods: A total of 173 consecutive patients with symptomatic severe AS who underwent TAVI were included retrospectively. The primary endpoint of the study was the development of AKI. Study population was divided into two groups according to the presence of AKI. The ACEF score was calculated with the formula: age/EF +1 (if baseline creatinine $>2 \mathrm{mg} / \mathrm{dl}$ ).

Results: Twenty-nine patients developed AKI. The median (interquartile range) ACEF score was 1.36 (1.20-1.58). The ACEF score was found to be an independent predictor of AKI $(P<0.001)$. The ACEF score $\geq 1.36$ predicted AKI development with a sensitivity of $96.6 \%$ and specificity of $58.8 \%$. Moreover, hypertension, hemoglobin levels, contrast volume, and aortic valve area (AVA) were found to be independent predictors of AKI.

Conclusions: Our study revealed that the ACEF score was an independent predictor of AKI. A simple and objective score might be very useful in predicting AKI development in patients undergoing TAVI.

Key words: ACEF score, acute kidney injury, transcatheter aortic valve implantation

Kardiol Pol 2021; 79, 6: 662-668

\section{INTRODUCTION}

Severe aortic stenosis (AS) is a common heart valve disease, especially in the elderly population and the most common treatment method used in these patients is surgical aortic valve replacement (SAVR) [1]. Transcatheter aortic valve implantation (TAVI) has emerged as a new and innovative approach to the treatment of severe AS [2, 3]. TAVI has become an effective, less invasive, and safe alternative treatment option for patients with severe AS who are not suitable for SAVR or who are considered to be at high surgical risk, and in patients with old age and some comorbidities [2, 3]. Recently, several trials have reported that TAVI can be considered an important alternative to SAVR even in patients with low and intermediate surgical risk. A surgical replacement and transcatheter aortic valve implantation trial focused on intermediate risk patients and revealed that
TAVI is not inferior to SAVR [4], PARTNER 3 and Evolut Low Risk trials investigated the low-risk patients, and presented that TAVI is not inferior [5] or is even superior [6] to SAVR in terms of clinical outcomes.

Acute kidney injury (AKI) occurs after TAVI due to several factors including comorbidities of the patients, hemodynamic alterations during the procedure, and pre- or periprocedural contrast media usage [3]. Several studies investigated the utility of baseline, procedural characteristics or risk scores in predicting AKI following TAVI. These studies revealed that the development of AKI was closely associated with the patients' poor clinical outcome [7-10]. The age, creatinine, ejection fraction (ACEF) score is a simple scoring method that includes only three parameters and was originally developed to predict mortality in patients undergoing elective coronary 
WHAT'S NEW?

In this manuscript, we presented that the age, creatinine, ejection fraction (ACEF) score is an independent predictor of acute kidney injury (AKI) in patients who underwent transcatheter aortic valve implantation (TAVI). A simple and objective score can be very useful in predicting AKI development. To the best of our knowledge, our study is the first that focuses on the relationship between the ACEF score and AKI development in TAVI patients.

artery bypass graft surgery [11]. Also, some investigators have examined ACEF, predicting mortality and clinical outcomes in patients undergoing percutaneous coronary intervention (PCI) [12-15]. The ACEF score has been previously studied for predicting mortality in patients who underwent TAVI but has not been fully investigated in predicting AKI. In the present study, we aimed to evaluate the utility of the ACEF score in predicting AKI in patients who underwent TAVI.

\section{METHODS}

\section{Study population}

This retrospective cohort study enrolled a total of 188 consecutive patients with symptomatic severe AS who underwent TAVI between December 2017 and June 2020 in the University Of Health Sciences Istanbul Mehmet Akif Ersoy Thoracic And Cardiovascular Surgery Training and Research Hospital, Turkey. Data was obtained after a systematic review of the patients' hospital records. The decision of TAVI was rendered with the consensus of a heart team involving cardiovascular surgeons, cardiologists, anesthesiologists, and pulmonologists. The preoperative risk was assessed with the European System for Cardiac Operative Risk Evaluation (EuroSCORE) or Society of Thoracic Surgeons (STS) risk calculator systems. Symptomatic severe AS patients who met transthoracic echocardiographic criteria at rest or with a dobutamine stress test in case of left ventricular impairment were included in study. Severe AS was defined as mean gradient $>40 \mathrm{~mm} \mathrm{Hg}$, velocity $>4.0 \mathrm{~m} / \mathrm{s}$, aortic valve area $(A V A)<1 \mathrm{~cm}^{2}$ or Indexed AVA $<0.6 \mathrm{~cm}^{2} / \mathrm{m}^{2}$. Exclusion criteria were the absence of all medical records, already on the treatment of dialysis, patients who died during the procedure or within 72 hours after the procedure. 10 patients who were already on the hemodialysis treatment before the procedure and 5 patients who died during the procedure or in the first 72 hours were excluded from the study, and, finally, 173 patients were included in this study. The study protocol was approved by the Local Ethics Committee and the study conforms to the principles outlined in the Declaration of Helsinki.

\section{Procedural details}

The TAVI procedures were performed in a sterile environment in the catheterization laboratory under conscious sedation or general anesthesia. A transfemoral or transapical approach was used during the procedure. After the procedures, the patients were taken to the intensive care unit and followed up with non-invasive tests (including transthoracic echocardiographic, electrocardiography, and laboratory tests).

\section{Clinical assessment and procedural complications}

Transient ischemic stroke was defined as brief episodes of neurological dysfunction resulting from focal cerebral ischemia not associated with permanent cerebral infarction [16]. Moreover, ischemic stroke was defined as an episode of neurological dysfunction caused by focal cerebral, spinal, or retinal infarction [17]. These embolic events, the presence of clinical signs was confirmed by imaging modalities (magnetic resonance imaging with or without computed tomography angiography). The clinical diagnosis of a transient ischemic stroke, stroke, and hemorrhage was made by a neurologist. Vascular complications were categorized according to Valve Academic Research Consortium modified classification as major and minor vascular complications. Thoracic aortic dissection, access site-related vascular injury (including dissection, stenosis, perforation, rupture, arterio-venous fistula, pseudoaneurysm, hematoma $>5 \mathrm{~cm}$, irreversible nerve injury or compartment syndrome requiring $>3$ red blood cell units transfusion, peripheral embolization requiring surgical intervention or amputation, and left ventricular perforation were considered as major complications. Among the vascular complications, those not suitable for major complications were defined as minor complications.

Clinical histories, physical examinations, cardiovascular risk factors, pre-and post-procedural non-invasive laboratory studies, catheterization data such as implanted valve type and size, contrast volume used in the procedure, and procedural complications of the patients were reviewed and recorded. Serum creatinine levels ( $\mathrm{mg} / \mathrm{dl}$ ) were measured within 24 hours before the procedure, immediately after the procedure, and daily until the patient was discharged. The ACEF score was calculated according to the following formula: $\mathrm{ACEF}=$ age/left ventricular ejection fraction (\%) + 1 (if creatinine was $>2.0 \mathrm{mg} / \mathrm{dl}$ ).

\section{Study endpoint}

The primary endpoint of the study was the development of AKI. The AKI was defined according to Valve Academic Research Consortium-2 standardized endpoint definitions as a change in serum creatinine $\leq 72$ hours postprocedure [18].

AKI diagnosis was made according to the following 3 major criteria: 1 ) increase in serum creatinine $\geq 1.5$ times 
compared with baseline, or 2 ) increase of $\geq 0.3 \mathrm{mg} / \mathrm{dl}$ ( $\geq 26.4 \mathrm{mmol} / \mathrm{l})$, or 3 ) urine output $<0.5 \mathrm{ml} / \mathrm{kg} / \mathrm{h}$ for $>6 \mathrm{~h}$.

\section{Statistical analysis}

Data were analyzed using the Statistical Package for the Social Sciences, version 24.0 (SPSS Inc., Chicago, Illinois, USA). Whether the variables show normal distribution; visual (histograms, probability curves) and analytical methods (Kolmogorov-Smirnov and Shapiro-Wilk) were evaluated. Numerical variables showing normal distribution were mean (standard deviation [SD]), numerical variables not showing normal distribution were expressed as median (interquartile range), and categorical variables as a percentage (\%). Numerical variables were evaluated using Student t-tests and the Mann-Whitney U-test between the two groups. The chi-square or Fisher exact test were used to comparing categorical variables. Covariates including all baseline and procedural characteristics exhibiting significant $P$-value in the univariable analysis were included in a logistic regression analysis to determine the predictive factors of the incidence of AKI. Receiver operating characteristic curve analysis and Youden index ( $\max$ [sensitivity + specificity - 1]) were used to determine the ideal ACEF cut-off value for predicting AKI. Throughout the present study, a $P$-value of $<0.05$ was considered significant.

\section{RESULTS}

We identified a total of 173 patients (mean age [SD]: 78.2 [7.4] years, male: 64) who underwent TAVI and met the inclusion criteria of the study. Patients were divided into two groups according to the presence of AKI as AKI $(+)$ and AKI (-) groups. Twenty-nine patients were in AKI (+) group and 144 patients were in AKI (-) group. Except for age, demographic parameters were not significantly different between the two groups $(P<0.001)$. However, hypertension rate was significantly higher $(P=0.04)$, and glomerular filtration rate was significantly lower in AKI (+) group $(P<0.001)$. Also, hemoglobin levels were significantly lower in $\mathrm{AKI}(+)$ group $(P=0.005)$. AKI $(+)$ group had significantly lower left ventricular EF (LVEF) $(P<0.001)$ and higher STS score $(P<0.001)$. The median (IQR) ACEF score was 1.36 (1.20-1.58) and AKI (+) group had significantly higher ACEF score (AKI [-]: 1.29 [1.15-1.46] vs AKI [+]: 1.64 [1.44-1.98], $P<0.001$ ) (Supplementary material, Figure S1). There was no significant difference in terms of mean aortic valve gradient; however, AVA was significantly lower in $\mathrm{AKI}(+)$ group $(P=0.01)$. Table 1 shows the demographic, clinical, echocardiographic, and laboratory characteristics of the patients.

There was no difference between the groups in terms of the type (balloon or self-expandable) and sizes of the implanted valves. The contrast volume used during the procedure was significantly higher in $\mathrm{AKI}(+)$ group $(P=0.001)$. There was no statistically significant difference between the two groups in terms of minor vascular complications and stroke; however, major vascular complications were significantly higher in the AKI $(+)$ group $(P=0.003)$. AKI $(+)$ group had a higher rate of predilation before valve implantation $(P=0.002)$, no significant differences were found in terms of postdilatation, access site, and rapid ventricular pacing between groups. Procedural information is presented in Table 2.

The parameters which were found to be significant in univariable analysis were taken into multivariable logistic regression analysis to determine independent associates AKI. Although age, LVEF, and STS score were found to be

Table 1. Comparison of basal demographic, clinical, echocardiographic and laboratory characteristics of the patients

\begin{tabular}{|c|c|c|c|c|}
\hline & $\begin{array}{c}\text { All patients } \\
(n=173)\end{array}$ & $\begin{array}{c}\text { AKI (-) } \\
(n=144)\end{array}$ & $\begin{array}{c}\text { AKI (t) } \\
(n=29)\end{array}$ & $P$-value \\
\hline Age, years, mean (SD) & $78.2(7.4)$ & $77.1(7.3)$ & $83.5(5.8)$ & $<0.001$ \\
\hline Sex (male), n (\%) & $64(37.0)$ & $55(38.2)$ & $9(31.0)$ & 0.47 \\
\hline Diabetes mellitus, n (\%) & $58(33.5)$ & $49(34.0)$ & $9(31.0)$ & 0.76 \\
\hline Hypertension, n (\%) & $89(51.4)$ & $69(47.9)$ & $20(69.0)$ & 0.04 \\
\hline CAD, n (\%) & $115(66.5)$ & $96(66.7)$ & $19(65.5)$ & 0.91 \\
\hline PAD, n (\%) & $48(27.7)$ & $38(26.4)$ & $10(34.5)$ & 0.37 \\
\hline $\mathrm{PH}, \mathrm{n}(\%)$ & $51(29.5)$ & $40(27.8)$ & $11(37.9)$ & 0.27 \\
\hline COPD, n (\%) & $78(45.1)$ & $65(45.1)$ & $13(44.8)$ & 0.98 \\
\hline CVE, n (\%) & $4(2.3)$ & $2(1.4)$ & $2(6.9)$ & 0.13 \\
\hline STS score & $7.8(5.8-9.2)$ & $7.1(5.3-9.0)$ & $9.7(7.8-12.0)$ & $<0.001$ \\
\hline ACEF score, median (IQR) & $1.36(1.20-1.58)$ & $1.29(1.15-1.46)$ & $\begin{array}{c}1.64 \\
(1.44-1.98)\end{array}$ & $<0.001$ \\
\hline LVEF, \% & $60(55-65)$ & $60(55-65)$ & $50(40-58)$ & $<0.001$ \\
\hline Mean gradient, mm Hg, mean (SD) & $48.4(10.0)$ & $47.8(9.6)$ & $51.3(11.5)$ & 0.09 \\
\hline AVA, $\mathrm{cm}^{2}$, mean (SD) & $0.75(0.13)$ & $0.76(0.13)$ & $0.69(0.14)$ & 0.010 \\
\hline Hemoglobin, g/dl, mean (SD) & $11.0(1.6)$ & $11.2(1.6)$ & $10.3(1.4)$ & 0.005 \\
\hline Creatinine, mg/dl, median (IQR) & $1.00(0.83-1.20)$ & $0.98(0.82-1.15)$ & $1.04(0.90-1.30)$ & 0.06 \\
\hline GFR, $\mathrm{ml} / \mathrm{min}$, mean (SD) & $65.9(18.9)$ & $68.8(18.5)$ & $51.7(14.1)$ & $<0.001$ \\
\hline
\end{tabular}

Data is presented as percentage, mean (SD) or median (IQR).

Abbreviations: ACEF, age, creatinine, ejection fraction; AKI, acute kidney injury; AVA, aortic valve area; CAD, coronary artery disease; COPD, chronic obstructive pulmonary disease; CVE, cerebrovascular event; GFR, glomerular filtration rate; LVEF, left ventricular ejection fraction; PAD, peripheral artery disease; PH, pulmonary hypertension; STS, Society of Thoracic Surgeons 
Table 2. Comparison of the groups according to the procedural features

\begin{tabular}{|c|c|c|c|c|}
\hline & $\begin{array}{l}\text { All patients } \\
(n=173)\end{array}$ & $\begin{array}{c}\text { AKI (-) } \\
(n=144)\end{array}$ & $\begin{array}{l}\text { AKI (+) } \\
(n=29)\end{array}$ & $P$-value \\
\hline Balloon expandable & $86(49.7)$ & $73(50.7)$ & $13(44.8)$ & 0.56 \\
\hline Self-expandable & $87(50.3)$ & $71(49.3)$ & $16(55.2)$ & 0.56 \\
\hline Valve size, median (IQR) & $27(26-29)$ & $27(26-29)$ & $29(26-29)$ & 0.72 \\
\hline Contrast volume, ml, median (IQR) & $125(100-160)$ & $120(95-154)$ & $150(130-193)$ & 0.001 \\
\hline Major vascular complication & $11(6.4)$ & $5(3.5)$ & $6(20.7)$ & 0.003 \\
\hline Minor vascular complication & $38(22.0)$ & $33(22.9)$ & $5(17.2)$ & 0.50 \\
\hline Stroke & $8(4.6)$ & $6(4.2)$ & $2(6.9)$ & 0.62 \\
\hline Post-op blood transfusion & $40(23.1)$ & $29(20.1)$ & $11(37.9)$ & 0.04 \\
\hline Predilatation & $75(43.4)$ & $55(38.2)$ & $20(69.0)$ & 0.002 \\
\hline Postdilatation & $48(27.7)$ & $40(27.8)$ & $8(27.6)$ & 0.98 \\
\hline Rapid pacing & $139(80.3)$ & $117(81.3)$ & $22(75.9)$ & 0.51 \\
\hline Access site (apical) & $6(3.5)$ & $5(3.5)$ & $1(3.4)$ & 1.0 \\
\hline
\end{tabular}

Data are presented as number (percentage) of patients unless otherwise indicated.

Abbreviations: see Table 1

Table 3. Univariable and multivariable analysis for detecting the predictors of acute kidney injury following transcatheter aortic valve implantation

\begin{tabular}{|c|c|c|c|c|}
\hline & \multicolumn{2}{|c|}{ Univariate analysis } & \multicolumn{2}{|c|}{ Multivariate analysis } \\
\hline & OR $(95 \% \mathrm{CI})$ & $P$-value & OR $(95 \% \mathrm{CI})$ & $P$-value \\
\hline Age, & $1.140(1.068-1.218)$ & $<0.001$ & & \\
\hline Hypertension & $5.217(1.886-14.432)$ & 0.001 & $15.310(3.283-71.398)$ & 0.001 \\
\hline Creatinine & $2.745(0.843-8.942)$ & 0.09 & & \\
\hline STS & $1.316(1.153-1.503)$ & $<0.001$ & & \\
\hline LVEF & $0.927(0.893-0.962)$ & $<0.001$ & & \\
\hline ACEF score & $7.142(2.648-19.264)$ & $<0.001$ & $22.911(5.104-102.84)$ & $<0.001$ \\
\hline AVA & $0.018(0.001-0.413)$ & 0.01 & $0.009(<0.001-0.957)$ & 0.048 \\
\hline Hemoglobin & $0.560(0.491-0.889)$ & 0.006 & $0.388(0.242-0.622)$ & $<0.001$ \\
\hline Contrast volume & $1.006(1.000-1.012)$ & 0.04 & $1.016(1.007-1.026)$ & 0.001 \\
\hline Predilatasyon & $3.596(1.529-8.460)$ & 0.003 & $2.373(0.787-7.633)$ & 0.15 \\
\hline
\end{tabular}

Abbreviations: see Table 1

significant in the univariable analysis, they were not included in the multivariable analysis because age and LVEF are the components of ACEF score, and the ACEF score parameters exists in the STS score. Hypertension (OR, 15.31; 95\% Cl, 3.28-71.40; $P=0.001)$, ACEF score (OR, 22.91; 95\% $\mathrm{Cl}, 5.10-102.84 ; P<0.001)$, hemoglobin levels (OR, 0.39; $95 \% \mathrm{Cl}, 0.24-0.62 ; P<0.001)$, contrast volume (OR, 1.016; $95 \% \mathrm{Cl}, 1.007-1.026 ; P=0.001)$, and AVA (OR, 0.009; 95\% $\mathrm{Cl},<0.001-0.957 ; P=0.048$ ) were found to be independent predictors of AKI (Table 3 ).

Receiver operating characteristic analysis was generated to detect the optimal cut-off value of the ACEF score in predicting AKI (Supplementary material, Figure S2). The ACEF score higher than 1.36 predicted AKI with a sensitivity of $96.6 \%$, specificity of $58.8 \%$, positive predictive value of $34.1 \%$, negative predictive value of $98.7 \%$, and accuracy of $65.6 \%$ (area under curve [AUC]: $0.821 ; 95 \% \mathrm{Cl}, 0.752-0.891$; $P<0.001)$.

\section{DISCUSSION}

In the present study, we evaluated the effect of the ACEF score and other traditional AKI risk parameters on AKI development in patients who underwent TAVI. Three major findings of the current study are: 1) an ACEF score was an independent predictor of AKI in TAVI patients; 2) an ACEF score $\geq 1.36$ predicted AKI with the sensitivity of $96.6 \%$ and specificity of $58.8 \%$; 3 ) hypertension, hemoglobin levels, contrast volume, and AVA were also found to be independent predictors of AKI following TAVI.

The ACEF score is a very simple scoring system that includes only 3 parameters: age, creatinine, and LVEF. Previously, it was found to be associated with AKI following primary $\mathrm{PCl}[15,19]$ and coronary catheterization [20]. The ACEF score has previously been studied in patients undergoing TAVI, but most of these studies focused on predicting mortality from the ACEF score [21, 22]. In addition, previously, some studies showed the relationship between increasing age and AKI development in TAVI patients [23], nevertheless, some studies revealed that there was no statistically significant relationship between age and AKI development $[9,10,24]$. Although low LVEF has previously been reported to be an important predictor of AKI development [23, 24], Pyxaras et al. [25] indicated that low LVEF is not associated with the development of AKI after TAVI. Moreover, Elhmidi et al. showed that preprocedural creatinine level was a predictor of AKI [26]; however, some 
investigators revealed no relation between creatinine levels and AKI development [25]. In our study, we found that age and LVEF were associated with AKI in TAVI patients, whereas creatinine level was not associated with the development of AKI. Based on the results of previous studies and our study, the effects of these three parameters on AKI development after TAVI are still controversial. The combination of multiple parameters increases the accuracy of risk models; however, including too many parameters will be difficult in daily clinical use. The main benefit of the ACEF score is its easy accessibility, three parameters, and simple calculability. Our study showed that the ACEF score was an independent predictor of AKI in patients undergoing TAVI. In the current literature, several studies were reported on the short and long-term mortality after TAVI procedure or comparison of the ACEF score with the other scores. In addition to our research, only Arai et al. [27] investigated the development of AKI in this patient population. However, they investigated the development of AKI with a modified ACEF score, which included creatinine clearance instead of creatinine. They also found that the modified ACEF score is an independent predictor of AKI. Gender, age, weight, and creatinine values are used in the calculation of creatinine clearance. Creatinine clearance is a better predictor of AKI when compared to serum creatinine in the patients who underwent coronary artery bypass graft surgery [28, 29] and the modified ACEF score has been reported to increase the accuracy of the original ACEF score among $\mathrm{PCl}$ patients [30-32]. However, there is no study comparing modified ACEF and original ACEF in TAVI patients. In our study, we can comment that both original and modified ACEF scores predict AKI in patients undergoing TAVI. To the best of our knowledge, there is no study which focuses fully on the role of ACEF score in predicting AKI in TAVI patients.

The relationship between contrast volume and AKI development is also controversial. Previously, Barbash et al. reported that there was no statistical difference in the contrast volume used during the procedure between the groups with and without AKI $(117 \pm 88 \mathrm{ml}$ vs $98 \pm 46 \mathrm{ml}$, $P=0.13$ ) [26]. In another study, it was shown that there was no statistical difference between AKI stages and contrast volume (103.84 $\pm 58.53 \mathrm{ml}$ vs $122.61 \pm 96.79 \mathrm{ml}, P=0.78)$ [33]. In 2012, Madershahian et al. [34] evaluated the risk of AKI after TAVI and reported a significantly increased risk of AKI when comparing patients who received a contrast volume of $>100 \mathrm{ml}$ vs $<100 \mathrm{ml}$ of contrast volume. A recent metaanalysis by Thongprayoon et al. [35] demonstrated no association between high contrast media volume and the risk of AKI following TAVI. Hence, the dose of contrast media may not play a significant role in the pathogenesis of TAVI-related AKI. This finding will likely impact the direction of future studies for TAVI-related AKI prevention. In contrast to the findings, Yamamoto et al. [24] indicated that a relationship between contrast volume increment and high prevalence of AKI. Although contrast volume was not identified as an independent predictor of AKI after TAVI in previous reports [26, 33-35], it is still of utmost importance to establish whether contrast volume should be limited in TAVI procedures carried out in an elderly and high risk cohort [36]. Similar to the findings of Yamamoto et al. [24], in the present study, we found that contrast volume was an independent predictor of AKI development in TAVI patients. In a review article, Legnazzi et al. [37] reported how to prevent contrast induced AKI in the patients undergoing $\mathrm{PCl}$ in detail. These approaches might be applied to the TAVI patients to avoid AKI development, however it should be supported with large prospective studies. We also found that hypertension was one of the independent predictors of $\mathrm{AKI}$, which is consistent with the current literature $[23,36]$.

In the present study, AKI (+) group had significantly lower hemoglobin levels, and lower hemoglobin levels were found to be the independent predictors of AKI. Previously, Nuis et al. [38] revealed that periprocedural anemia was not associated with AKI after TAVI procedures. Hence, the relationship between hemoglobin levels and the development of AKI is still controversial. Larger randomized studies are needed to confirm the relationship between hemoglobin levels and AKI development.

The present study has several limitations. First of all, this was a single-center, retrospective study, and included a relatively small patient population. Thus, large prospective cohort studies are needed to fully appreciate and validate our findings. Second, there was no standard pre- and post-hydration regimen for patients who underwent TAVI.

In conclusion, our study showed that a simple and objective score, ACEF, may predict AKI development in patients who underwent TAVI.

\section{Supplementary material}

Supplementary material is available at https://journals. viamedica.pl/kardiologia_polska.

\section{Article information}

Conflict of interest: None declared.

Open access: This article is available in open access under Creative Common Attribution-Non-Commercial-No Derivatives 4.0 International (CC BY-NC-ND 4.0) license, allowing to download articles and share them with others as long as they credit the authors and the publisher, but without permission to change them in any way or use them commercially. For commercial use, please contact the journal office at kardiologiapolska@ptkardio.pl.

How to cite: Uygur B, Celik O, Demir AR, et al. A simplified acute kidney injury predictor following transcatherer aortic valve implantation: ACEF score. Kardiol Pol. 2021; 79(6): 662-668, doi: 10.33963/KP.15933.

\section{REFERENCES}

1. Stewart BF, Siscovick D, Lind BK, et al. Clinical factors associated with calcific aortic valve disease. Cardiovascular Health Study. J Am Coll Cardiol. 1997; 29(3): 630-634, doi: 10.1016/s0735-1097(96)00563-3, indexed in Pubmed: 9060903.

2. Leon $M B$, Smith $C R$, Mack $M$, et al. PARTNER Trial Investigators. Transcatheter aortic-valve implantation for aortic stenosis in patients who cannot undergo surgery. N Engl J Med. 2010; 363(17): 1597-1607, doi: 10.1056/NEJMoa1008232, indexed in Pubmed: 20961243. 
3. Smith C, Leon M, Mack M, et al. Transcatheter versus surgical aortic-valve replacement in high-risk patients. N Engl J Med. 2011;364(23):2187-2198, doi: 10.1056/nejmoa1103510, indexed in Pubmed: 21639811.

4. Reardon MJ, Van Mieghem NM, Popma JJ, et al. SURTAVI Investigators. Surgical or transcatheter aortic-valve replacement in intermediate-risk patients. N Engl J Med. 2017; 376(14): 1321-1331, doi: 10.1056/NEJMoa1700456, indexed in Pubmed: 28304219.

5. Popma JJ, Deeb GM, Yakubov SJ, et al. Evolut Low Risk Trial Investigators. Transcatheter aortic-valve replacement with a self-expanding valve in low-risk patients. N Engl J Med. 2019; 380(18): 1706-1715, doi: 10.1056/NEJMoa1816885, indexed in Pubmed: 30883053.

6. Mack MJ, Leon MB, Thourani VH, et al. PARTNER 3 Investigators. Transcatheter aortic-valve replacement with a balloon-expandable valve in low-risk patients. N Engl J Med. 2019;380(18): 1695-1705, doi: 10.1056/NEJMoa1814052, indexed in Pubmed: 30883058.

7. Wang J, Yu W, Zhou Ye, et al. Independent risk factors contributing to acute kidney injury according to updated valve academic research consortium-2 criteria after transcatheter aortic valve implantation: a meta-analysis and meta-regression of 13 studies. J Cardiothorac Vasc Anesth. 2017; 31(3): 816-826, doi: 10.1053/j.jvca.2016.12.021, indexed in Pubmed: 28385646.

8. Langfritz $M$, Shahin $M$, Nietlispach $F$, et al. Baseline predictors of renal failure in transcatheter aortic valve implantation. J Invasive Cardiol. 2019; 31(10): E289-E297, indexed in Pubmed: 31567117.

9. Zungur M, Gul I, Tastan A, et al. Predictive value of the mehran score for contrast-induced nephropathy after transcatheter aortic valve implantation in patients with aortic stenosis. Cardiorenal Med. 2016;6(4):279-288, doi: 10.1159/000443936, indexed in Pubmed: 27648009.

10. Gul I, Zungur M, Tastan A, et al. The importance of contrast volume/glomerular filtration rate ratio in contrast-induced nephropathy patients after transcatheter aortic valve implantation. Cardiorenal Med. 2015; 5(1): 31-39, doi: 10.1159/000369943, indexed in Pubmed: 25759698.

11. Ranucci M, Castelvecchio S, Menicanti $L$, et al. Risk of assessing mortality risk in elective cardiac operations: age, creatinine, ejection fraction, and the law of parsimony. Circulation. 2009; 119(24): 3053-3061, doi: 10.1161/CIRCULATIONAHA.108.842393, indexed in Pubmed: 19506110.

12. Wykrzykowska JJ, Garg S, Onuma Y, et al. Value of age, creatinine, and ejection fraction (ACEF score) in assessing risk in patients undergoing percutaneous coronary interventions in the 'All-Comers' LEADERS trial. Circ Cardiovasc Interv. 2011; 4(1): 47-56, doi: 10.1161/CIRCINTERVENTIONS.110.958389, indexed in Pubmed: 21205944.

13. Biondi-Zoccai G, Romagnoli E, Castagno D, et al. Simplifying clinical risk prediction for percutaneous coronary intervention of bifurcation lesions: the case for the ACEF (age, creatinine, ejection fraction) score. Eurolntervention. 2012; 8(3): 359-367, doi: 10.4244/EIJV8I3A55, indexed in Pubmed: 22584142.

14. Lee JH, Bae MH, Yang DH, et al. Korea Acute Myocardial Infarction Registry Investigators. Prognostic value of the age, creatinine, and ejection fraction score for 1-year mortality in 30-day survivors who underwent percutaneous coronary intervention after acute myocardial infarction. Am J Cardiol. 2015; 115(9): 1167-1173, doi: 10.1016/j.amjcard.2015.02.001, indexed in Pubmed: 25772739.

15. Araujo GN, Pivatto Junior F, Fuhr B, et al. Simplifying contrast-induced acute kidney injury prediction after primary percutaneous coronary intervention: the age, creatinine and ejection fraction score. Cardiovasc Interv Ther. 2018; 33(3): 224-231, doi: 10.1007/s12928-017-0472-y, indexed in Pubmed: 28540634.

16. Easton JD, Saver JL, Albers GW, et al. American Heart Association, American Stroke Association Stroke Council, Council on Cardiovascular Surgery and Anesthesia, Council on Cardiovascular Radiology and Intervention, Council on Cardiovascular Nursing, Interdisciplinary Council on Peripheral Vascular Disease. Definition and evaluation of transient ischemic attack: a scientific statement for healthcare professionals from the American Heart Association/American Stroke Association Stroke Council; Council on Cardiovascular Surgery and Anesthesia; Council on Cardiovascular Radiology and Intervention; Council on Cardiovascular Nursing; and the Interdisciplinary Council on Peripheral Vascular Disease. The American Academy of Neurology affirms the value of this statement as an educational tool for neurologists. Stroke. 2009; 40(6): 2276-2293, doi: 10.1161/STROKEAHA.108.192218, indexed in Pubmed: 19423857.
17. Sacco RL, Kasner SE, Broderick JP, et al. American Heart Association Stroke Council, Council on Cardiovascular Surgery and Anesthesia, Council on Cardiovascular Radiology and Intervention, Council on Cardiovascular and Nursing, Council on Epidemiology and Prevention, Council on Peripheral Vascular Disease, Council on Nutrition, Physical Activity and Metabolism. An updated definition of stroke for the 21st century: a statement for healthcare professionals from the American Heart Association/American Stroke Association. Stroke. 2013; 44(7): 2064-2089, doi: 10.1161/STR.0b013e318296aeca, indexed in Pubmed: 23652265.

18. Kappetein AP, Head SJ, Généreux $P$, et al. Valve Academic Research Consortium (VARC)-2. Updated standardized endpoint definitions for transcatheter aortic valve implantation: the Valve Academic Research Consortium-2 consensus document (VARC-2). Eur J Cardiothorac Surg. 2012; 42(5): S45-S60, doi: 10.1093/ejcts/ezs533, indexed in Pubmed: 23026738.

19. Liu YH, Liu Y, Zhou YL, et al. Comparison of different risk scores for predicting contrast induced nephropathy and outcomes after primary percutaneous coronary intervention in patients with ST elevation myocardial infarction. Am J Cardiol. 2016; 117(12): 1896-1903, doi: 10.1016/j. amjcard.2016.03.033, indexed in Pubmed: 27161818.

20. Capodanno D, Ministeri M, Dipasqua F, et al. Risk prediction of contrast-induced nephropathy by ACEF score in patients undergoing coronary catheterization. J Cardiovasc Med (Hagerstown). 2016; 17(7): 524-529, doi: 10.2459/JCM.0000000000000215, indexed in Pubmed: 25304032.

21. Zbroński K, Huczek Z, Puchta D, et al. Outcome prediction following transcatheter aortic valve implantation: Multiple risk scores comparison. Cardiol J. 2016; 23(2): 169-177, doi: 10.5603/CJ.a2015.0081, indexed in Pubmed: 26711463.

22. Denegri A, Mehran R, Holy $E$, et al. Post procedural risk assessment in patients undergoing trans aortic valve implantation according to the age, creatinine, and ejection fraction-7 score: advantages of age, creatinine, and ejection fraction-7 in stratification of post-procedural outcome. Catheter Cardiovasc Interv. 2019; 93(1): 141-148, doi: 10.1002/ccd.27806, indexed in Pubmed: 30269398.

23. Ram P, Mezue K, Pressman G, et al. Acute kidney injury post-transcatheter aortic valve replacement. Clin Cardiol. 2017; 40(12): 1357-1362, doi: 10.1002/clc.22820, indexed in Pubmed: 29251358.

24. Yamamoto M, Hayashida K, Mouillet G, et al. Renal function-based contrast dosing predicts acute kidney injury following transcatheter aortic valve implantation. JACC Cardiovasc Interv. 2013;6(5):479-486, doi: 10.1016/j. jcin.2013.02.007, indexed in Pubmed: 23702012.

25. Pyxaras $S A$, Zhang $Y$, Wolf $A$, et al. Effect of varying definitions of contrast-induced acute kidney injury and left ventricular ejection fraction on one-year mortality in patients having transcatheter aortic valve implantation. Am J Cardiol. 2015; 116(3): 426-430, doi: 10.1016/j.amjcard.2015.04.056, indexed in Pubmed: 26026866.

26. Elhmidi $Y$, Bleiziffer S, Piazza N, et al. Incidence and predictors of acute kidney injury in patients undergoing transcatheter aortic valve implantation. Am Heart J. 2011; 161(4): 735-739, doi: 10.1016/j.ahj.2011.01.009, indexed in Pubmed: 21473973.

27. Arai $T$, Lefèvre $T$, Hayashida $K$, et al. Usefulness of a simple clinical risk prediction method, modified ACEF score, for transcatheter aortic valve implantation. Circ J. 2015; 79(7): 1496-1503, doi: 10.1253/circj.CJ-14-1242, indexed in Pubmed: 25947002.

28. Walter J, Mortasawi A, Arnrich B, et al. Creatinine clearance versus serum creatinine as a risk factor in cardiac surgery. BMC Surg. 2003; 3: 4, doi: 10.1186/1471-2482-3-4, indexed in Pubmed: 12812527.

29. Noyez L, Plesiewicz I, Verheugt FWA. Estimated creatinine clearance instead of plasma creatinine level as prognostic test for postoperative renal function in patients undergoing coronary artery bypass surgery. Eur J Cardiothorac Surg. 2006;29(4): 461-465, doi: 10.1016/j.ejcts.2006.01.024, indexed in Pubmed: 16483789.

30. Garg S, Sarno G, Garcia-Garcia HM, et al. ARTS-II Investigators. A new tool for the risk stratification of patients with complex coronary artery disease: the Clinical SYNTAX Score. Circ Cardiovasc Interv. 2010; 3(4):317-326, doi: 10.1161/CIRCINTERVENTIONS.109.914051, indexed in Pubmed: 20647561.

31. Capodanno D, Marcantoni C, Ministeri M, et al. Incorporating glomerular filtration rate or creatinine clearance by the modification of diet in renal disease equation or the Cockcroft-Gault equations to improve the global accuracy of the age, creatinine, ejection fraction [ACEF] score in patients undergoing percutaneous coronary intervention. Int J Cardiol. 2013; 
168(1): 396-402, doi: 10.1016/j.ijcard.2012.09.026, indexed in Pubmed: 23041093.

32. Capodanno D. Beyond the SYNTAX score-advantages and limitations of other risk assessment systems in left main percutaneous coronary intervention. Circ J. 2013; 77(5): 1131-1138, doi: 10.1253/circj.cj-12-1613, indexed in Pubmed: 23546417.

33. GénéreuX $P$, Kodali SK, Green P, et al. Incidence and effect of acute kidney injury after transcatheter aortic valve replacement using the new valve academic research consortium criteria. Am J Cardiol. 2013; 111(1): 100-105, doi: 10.1016/j.amjcard.2012.08.057, indexed in Pubmed: 23040657.

34. Madershahian N, Scherner M, Liakopoulos $\mathrm{O}$, et al. Renal impairment and transapical aortic valve implantation: impact of contrast medium dose on kidney function and survival. Eur J Cardiothorac Surg. 2012; 41(6): 1225-1232, doi: 10.1093/ejcts/ezr 199, indexed in Pubmed: 22219473.

35. Thongprayoon C, Cheungpasitporn W, Podboy AJ, et al. The effects of contrast media volume on acute kidney injury after transcatheter aortic valve replacement: a systematic review and meta-analysis. J Evid Based Med. 2016; 9(4): 188-193, doi: 10.1111/jebm.12208, indexed in Pubmed: 27314627.

36. Najjar M, Salna M, George I. Acute kidney injury after aortic valve replacement: incidence, risk factors and outcomes. Expert Rev Cardiovasc Ther. 2015; 13(3): 301-316, doi: 10.1586/14779072.2015.1002467, indexed in Pubmed: 25592763.

37. Legnazzi M, Agnello F, Capodanno D. Prevention of contrast-induced acute kidney injury in patients undergoing percutaneous coronary intervention. Kardiol Pol. 2020; 78(10): 967-973, doi: 10.33963/KP.15537, indexed in Pubmed: 32735406.

38. Nuis RJ, Sinning JM, Rodés-Cabau J, et al. Prevalence, factors associated with, and prognostic effects of preoperative anemia on short- and long-term mortality in patients undergoing transcatheter aortic valve implantation. Circ Cardiovasc Interv. 2013;6(6): 625-634, doi: 10.1161/CIRCINTERVENTIONS.113.000409, indexed in Pubmed: 24280965. 